\title{
Дискретные конденсаторы на основе кремния
}

\author{
Н. Брюхно ${ }^{1}$, В. Громов ${ }^{2}$ М. Котова ${ }^{3}$, Ю. Севастьянов ${ }^{4}$, \\ В. Стрекалова ${ }^{5}$, В. Пугачев ${ }^{6}$
}

УДК 621.38 | ВАК 05.27 .01

\begin{abstract}
В статье приведен анализ конструкций дискретных конденсаторов на основе кремния ведущих производителей. Рассмотрены планарные и 3D-конденсаторы и связь их параметров с конструктивно-технологическим исполнением. Приведены результаты АО «ГРУППА КРЕМНИЙ ЭЛ" по разработке и освоению планарных СВЧ- и 3D-конденсаторов.
\end{abstract}

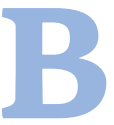

последнее десятилетие для изготовления конденсаторов широко используются кремний и материалы на его основе [1-4].

Выбор кремния обусловлен тем, что технология его обработки отличается высокой точностью и давно используется в микроэлектронике, а материалы на его основе (оксид и нитрид кремния) обладают уникальными диэлектрическими свойствами.

Существуют два типа кремниевых конденсаторов: планарный и 3D.

Планарные конденсаторы, изготовленные по тонкопленочной технологии, применяются для согласования импеданса высокочастотных транзисторов с источниками сигналов и полосковыми линиями, а также в СВЧ-фильтрах.

Эти конденсаторы являются составной частью конструкции высокочастотного транзистора [5-7]. Подложкой конденсаторов служит сильнолегированный бором кремний с удельным сопротивлением 0,005 Ом·см, что позволяет использовать в качестве первой обкладки конденсатора саму подложку. Применение бора обусловлено невысокой стоимостью кремния, легированного бором. Соотношение размеров сторон конденсаторов выбирают от 1:2 до 1: 9 [5], а контактные площадки к обкладкам ориентируют вдоль длинной стороны, что снижает последовательное сопротивление конденсатора на высоких частотах.

В качестве изолирующего диэлектрика используют слои нитрида кремния, оксида кремния, оксида алюминия и их комбинации, которые обладают высокой

\footnotetext{
Главный технолог УРМТиНТ, niko@sitsemi.ru.

Директор по развитию и новой технике, gromov@sitsemi.ru.

Инженер-технолог 3 кат., kotova@sitsemi.ru.

Директор производства кристаллов,

sevastyanov@kremny.032.ru.

Инженер-конструктор 2 кат., vismiokt@mail.ru.

Инженер-технолог, pugachev_vladimir@mail.ru
}

электрической прочностью, необходимой диэлектрической проницаемостью, требуемой стабильностью и защитными свойствами от воздействия окружающей среды. Толщина изолирующих слоев между обкладками - от 10 нм до 2 мкм. Толщина изолирующих слоев ограничивается (она не может быть большой), так как кремний и используемые материалы имеют разные по величине коэффициенты термического расширения, значения модуля Юнга и коэффициента Пуассона.

Нижняя и верхняя обкладки представляют собой металлические слои из алюминия или золота толщиной 1-2 мкм [6]. Наиболее широко используются электроды из золота. Для надежного нанесения золотых покрытий применяются тонкие адгезионные слои титана, а для исключения взаимодействия золотой металлизации нижней обкладки с кремнием - защитные слои платины. На обратную сторону кристаллов конденсаторов наносят 30лото для образования твердого припоя "кремний-золото". Выбирают толщину кристалла, равную толщине кристаллов транзисторов и микросхем гибридной сборки, обычно она составляет 100-250 мкм. Контактные площадки выполняют в виде участков металлизации обкладок или в виде выводных контактных шариков («бампов»).

Недостатком кремниевых планарных конденсаторов является их малая емкость - не более 2000 пФ из-за ограниченной площади обкладок. Этот недостаток устранен в кремниевых 3D-конденсаторах, у которых увеличение площади обкладок получают за счет формирования колодцев (trench), перпендикулярных рабочей плоскости обкладок [8]. Основной областью применения таких конденсаторов являются высокочастотные импульсные источники питания [9] и другие устройства, где требуются стабильные свойства конденсаторов в условиях изменения температуры окружающей среды.

Основные технологические особенности при конструировании и изготовлении кремниевых 3D-конденсаторовэто формирование колодцев, нанесение слоев диэлектрика и верхнего электрода в колодцы. 


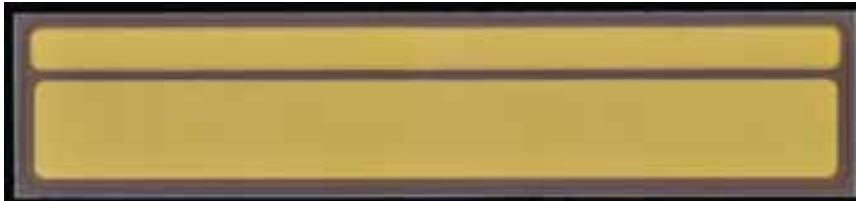

Рис. 1. Кристалл СВЧ-конденсатора на 83 пФ $(5,6 \times 0,75 \times 0,15 \mathrm{MM})$

Колодцы формируют двумя способами: реактивным ионным травлением в индуктивно связанной плазме или электрохимическим травлением [10, 11]. Форма, диаметр и глубина колодцев определяются емкостью и напряжением пробоя конденсаторов. Колодцы изготавливают в виде цилиндров, прямоугольников и в виде треноги. Колодцы в виде цилиндров имеют минимальный диаметр - 2 мкм. Глубина колодцев составляет 30-35 мкм. При больших глубинах сложно получить надежное заполнение колодцев диэлектриком и поликремнием. При изготовлении колодцев электрохимическим травлением используют кремний с концентрацией примеси меньшей, чем $10^{15} \mathrm{~cm}^{-3}$, что требует дополнительного сильного легирования поверхности колодцев. Травление в индуктивно связанной плазме не предъявляет требований к концентрации примеси в кремнии.

Диэлектриком в 3D-конденсаторах обычно являются многослойные системы: оксид кремния - нитрид кремния - оксид кремния (O-N-O) [12-14]. Сильнолегированный поликремний является верхним электродом конденсатора. Для снижения последовательного сопротивления в 3D-конденсаторах используют конструкцию с большим соотношением размеров сторон или матричное расположение множества выводов $[9,15]$.

АО «ГРУППА КРЕМНИЙ ЭЛ" имеет опытное производство планарных СВЧ-конденсаторов типа 8-202-ххх, 8-203-хxх и других по требованиям заказчика (рис. 1). В настоящее время выпускаются конденсаторы емкостью 19, 20, 57, 83, 85, 135 пФ.

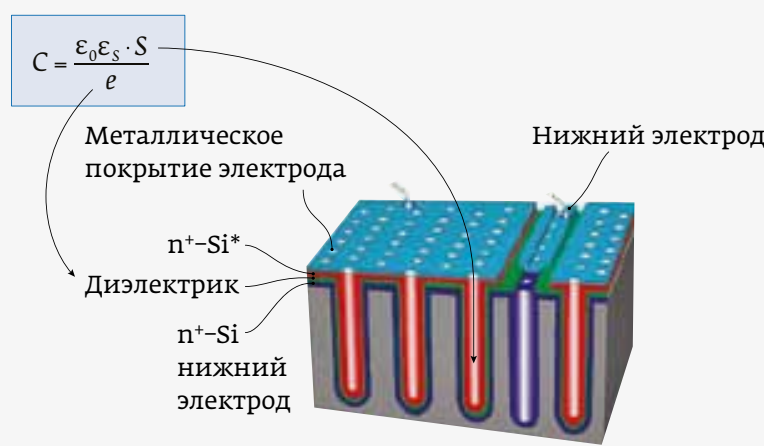

Рис. 3. Схема 3D-конденсатора

При использовании в качестве диэлектрика нитрида кремния при необходимости по периферии нижнего электрода формируют защитную полоску из оксида кремния, которая исключает трещины в диэлектрике [16]. Планарные СВЧ-конденсаторы, у которых нижний электрод соединен с кремнием при уменьшенной толщине защитного слоя платины под слоем золота нижнего электрода, повреждаются вследствие образования эвтектики «золото - кремний» (рис. 2).

Этот дефект устраняется путем контроля толщины платины

Если требуется емкость конденсатора меньшая, чем получается при использовании стандартных контактных площадок, то используют последовательное соединение конденсаторов [17]. В настоящее время АО «ГруППА КРЕМНИЙ ЭЛ» в рамках инициативных работ проводит серийное освоение 3D-конденсаторов, схема которых приведена на рис 3

Колодцы формируются в сильнолегированном кремнии [18] реактивно-ионным травлением в индуктивно связанной плазме (рис. 4, 5). Затем колодцы заполняются слоями диэлектриков и легированного поликремния газофазным химическим осаждением при пониженном давлении.

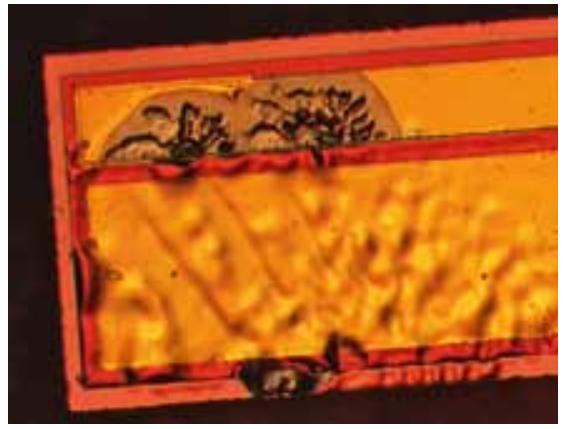

Рис. 2. Повреждение конденсатора из-за образования эвтектики

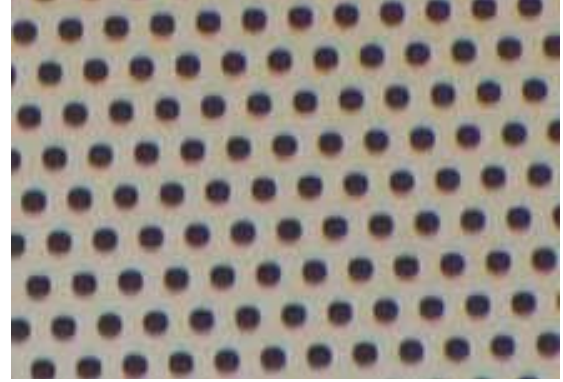

Рис. 4. Колодцы в кремнии: диаметр 3 мкм, шаг по стороне шестиугольника 7 мкм

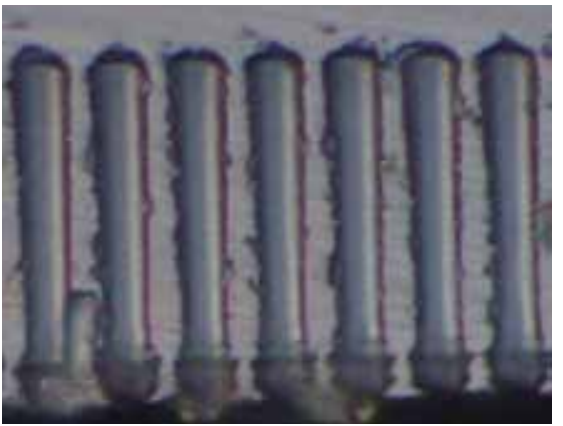

Рис. 5. Сечение колодцев глубиной 27 MKM 
Таблица 1. Конструктивные варианты 3D-конденсаторов

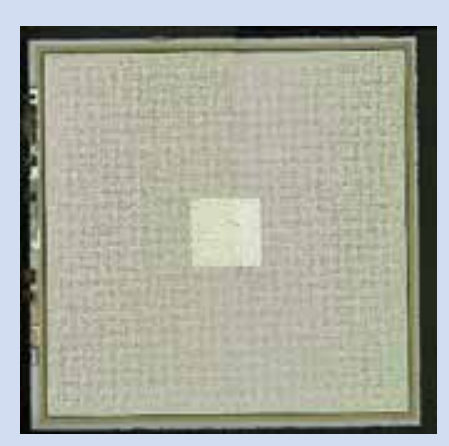

Верхний электрод - поликремний, покрытый алюминием, одна контактная площадка.

Нижний электрод на обратной стороне кристалла - эвтектика «золото - кремний»

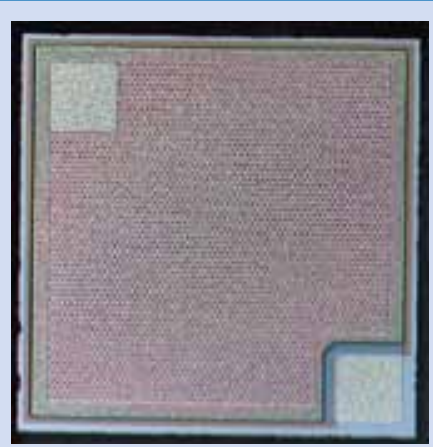

Верхний электрод - поликремний, покрытый алюминием, одна контактная площадка.

Нижний электрод - кремний, покрытый алюминием, одна контактная площадка на рабочей стороне кристалла.

На обратной стороне кристалла эвтектика "золото - кремний»

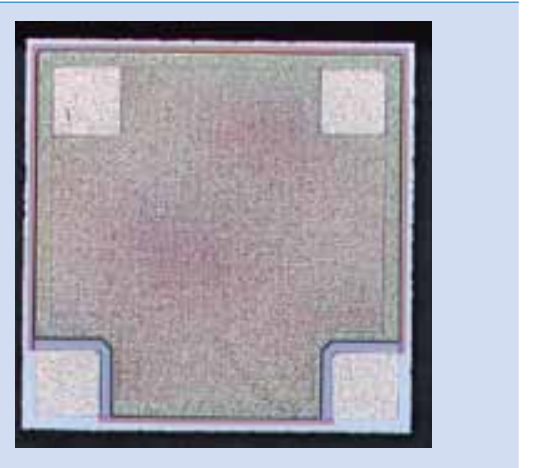

Верхний электрод - поликремний, покрытый алюминием, две контактные площадки.

Нижний электрод - кремний, покрытый алюминием, две контактные площадки на рабочей стороне кристалла.

На обратной стороне кристалла эвтектика "золото - кремний".

Последовательное сопротивление в два раза меньше
При изготовлении опытных конденсаторов использовались три конструктивных варианта размером 1,2×1,2 мм (табл. 1).

Так как электроды 3D-конденсатора не равнозначны: верхний электрод представляет собой совокупность цилиндрических остриев, покрытых диэлектриком и погруженных в колодцы в монокристаллическом кремнии нижнего электрода, то следует ожидать, что пробивное напряжение конденсатора будет зависеть от полярности на электродах. Эксперименты подтвердили это предположение.

При подаче отрицательного потенциала на острие напряжение пробоя выше, чем при подаче положительного потенциала. По-видимому, диэлектрик ведет себя,

Таблица 2. Зависимость напряжения пробоя от полярности потенциала на острие

\begin{tabular}{lcr} 
Tолщина & Полярность & Напряжение \\
диэлектрика, & потенциала & пробоя, \\
нкм & на острие & В \\
0,009 & - & 8 \\
\cline { 2 - 3 } & + & 4 \\
\hline 0,8 & - & 500 \\
\cline { 2 - 3 } & + & 500 \\
\hline
\end{tabular}

как газ в системе "острие - плоскость". При напряжениях пробоя больших, чем 50 В, эффект исчезает.

При исследовании высоковольтных конденсаторов по напряжению пробоя обнаружили эффект пробоя по воздуху на линию разделения конденсаторов (рис. 6). Эффект устраняется путем нанесения слоя защитного диэлектрика.

Основные свойства разработанных конденсаторов представлены в табл. 3.

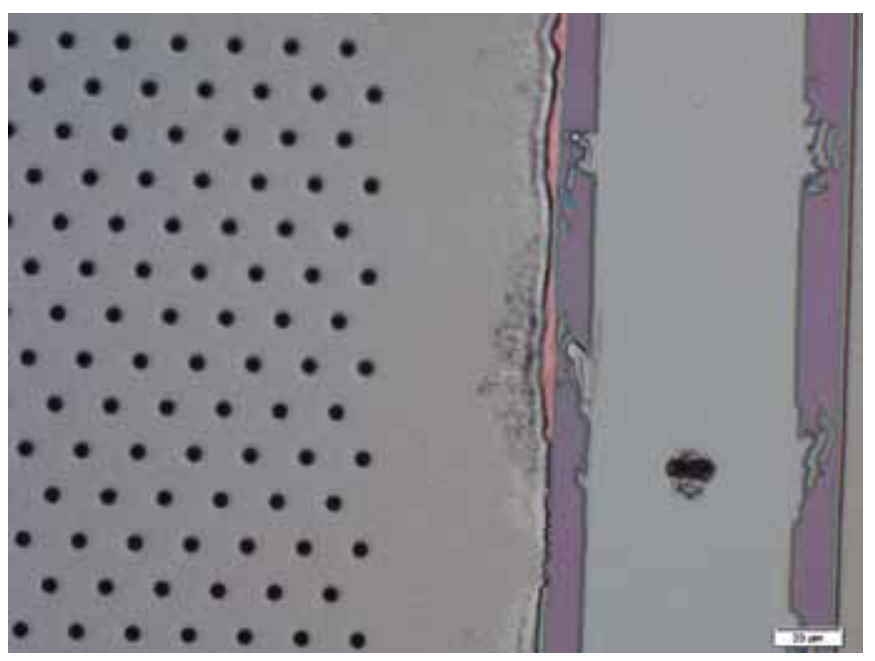

Рис. 6. Пробой конденсатора по воздуху на линию разделения на кристаллы 


\section{D Si-конденсаторы}

Основные характеристики:

- ёмкость: 10 пФ - 1 мкФ;

- напряжение пробоя: 6 - $400 \mathrm{~B}$;

- толщина конденсатора: 100 - 150 мкм;

- материал электродов: $\mathrm{Al}, \mathrm{Au}, \mathrm{Cu}$;

- глубина "колодцев": 30 - 35 мкм;

Основные преимущества:

- широкий диапазон рабочих температур $\left(-60 \ldots+250^{\circ} \mathrm{C}\right)$;

- высокая стабильность характеристик;

- минимальный тангенс угла потерь;

- высокая радиационная стойкость;

- миниатюрные размеры;

- гамма-процентная наработка до отказа не менее 150000 часов ( $\gamma=95 \%)$.

Состояние разработки:

опытная партия.

Размер кристалла 1,2×1,2 мм.

Способы монтажа:

- под разварку проволокой (C1, C2, С3);

- flip-chip монтаж

$(\mathrm{C} 4, \mathrm{C5}, \mathrm{C6})$;

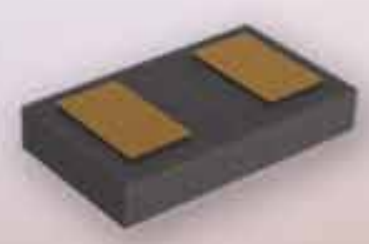

- в металлополимерном корпусе для поверхностного монтажа.

Размер корпуса : $1,4 \times 0,9 \times 0,4 \mathrm{~mm}$

(ёмкость $\leq 6$ нФ, рабочее напряжение 15 В).
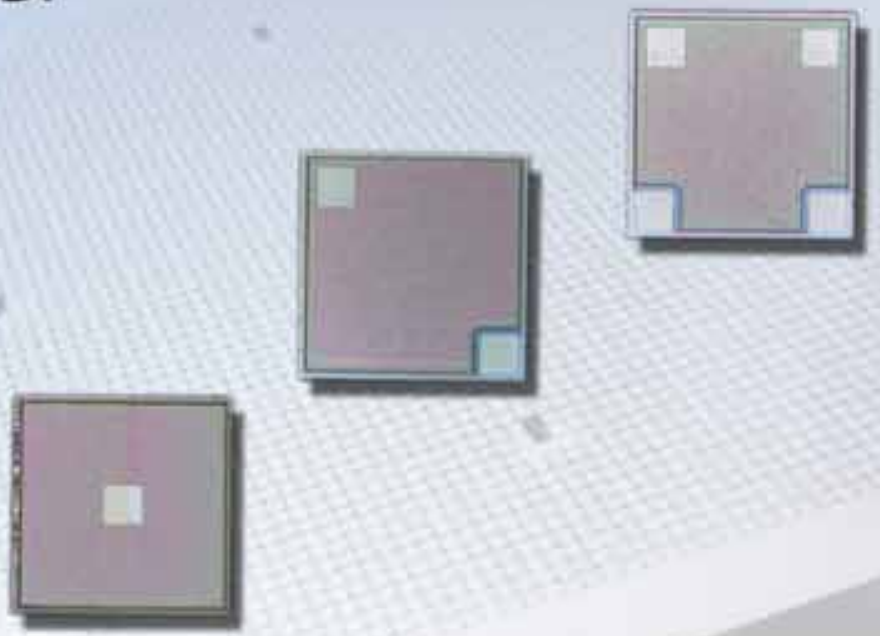

\begin{tabular}{|c|c|c|c|}
\hline $\begin{array}{c}\text { Tип } \\
\text { конденсатора }\end{array}$ & $\begin{array}{c}\text { Количество } \\
\text { контантных } \\
\text { площадок }\end{array}$ & $\begin{array}{c}\text { Емкость, } \\
\text { н\$ }\end{array}$ & $\begin{array}{c}\text { Рабочее } \\
\text { напряжение, } \\
\text { В }\end{array}$ \\
\hline C1 & 1 & 6 & 15 \\
\hline C2 & 2 & 5,8 & 15 \\
\hline C3 & 4 & 5,2 & 15 \\
\hline
\end{tabular}

\begin{tabular}{|c|c|c|c|c|c|}
\hline $\begin{array}{c}\text { Тип } \\
\text { конденсатора }\end{array}$ & $\begin{array}{c}\text { Млина, } \\
\text { мм }\end{array}$ & $\begin{array}{c}\text { ширина, } \\
\text { мм }\end{array}$ & $\begin{array}{c}\text { Толщина, } \\
\text { мм }\end{array}$ & $\begin{array}{c}\text { Емкость, } \\
\text { нФ }\end{array}$ & $\begin{array}{c}\text { Рабочее } \\
\text { напряжение, } \\
\text { В }\end{array}$ \\
\hline C4 & 0,6 & 0,3 & 0,1 & 1,5 & 15 \\
\hline C5 & 0,8 & 0,6 & 0,2 & 4 & 15 \\
\hline C6 & 1,2 & 0,7 & 0,2 & 6 & 15 \\
\hline
\end{tabular}
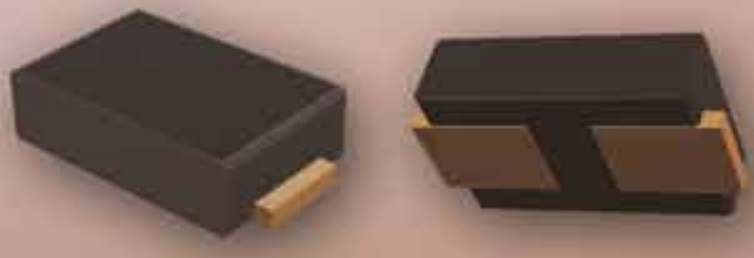

Техническая консультация

niko@sitsemi.ru

Ten. (4832) $66-58-22$

gromov@sitsemi.ru

тел. $(4832) 41-48-85$
241037, Россия, r. Брянск,

үл, Красноармейская, 103

Ten, (4832) 41-43.11

中akc $(4832)$ - $41-42 \cdot 14$ 
Таблица 3. Сравнительные характеристики кремниевых конденсаторов АО «ГРУППА КРЕМНИЙ ЭЛ"

\begin{tabular}{lll} 
& Планарные СВЧ Si-конденсаторы & 3D Si-конденсаторы \\
Емкость, пФ & $1-500$ & $50-1000000$ \\
\hline Напряжение пробоя, В & Не менее 100 & $5-400$ \\
\hline Толщина конденсатора, мкм & $120-150$ & $100-150$ \\
\hline Материал диэлектрика & Нитрид кремния & O-N-O \\
\hline Материал электродов & Pt-Au, $\mathrm{p}^{+} \mathrm{Si}-\mathrm{Au}$ & $\mathrm{Au}-\mathrm{n}^{+} \mathrm{Si} \mathrm{n}^{+}$поликремний-Al/ $\mathrm{Au}$ \\
\hline Глубина колодцев, мкм & - & $30-40$ \\
\hline
\end{tabular}

АО «ГРУППА КРЕМНИЙ ЭЛ» еще до завершения работ по освоению производства кремниевых конденсаторов может предоставить опытные образцы для более полного исследования свойств конденсаторов и успешного их применения потребителями и для выбора оптимальных вариантов конструкции.

\section{ЛИТЕРАТУРА}

1. 90xxx Series. Chip Capacitors [Электронный ресурс]. URL: https://www.macom.com/products/passives/ capacitors/mns,

https://www.macom.com/products/passives/capacitors/ mnos-series

2. MIS Silicon Chip Capacitors [Электронный ресурс]. URL: https://www.skyworksinc.com/

3. 3D Silicon Capacitors [Электронный ресурс]. URL: https://www.murata.com/en-sg/products/capacitor/ siliconcapacitors

4. Integrated Passive Devices and TSV, a disruptive technology for miniaturization [Электронный ресурс]. URL: https://www.murata.com/-/media/webrenewal/ products/capacitor/siliconcapacitors/technical/technology/ integrated_passive_devices_and_tsv.ashx?la=en

5. Зайцев А. А., Савельев Ю. Н. Генераторные СВЧ транзисторы. - М., Радио и связь, 1985. С. 7-8.

6. Дидилев С. Особенности использования золота и алюминия в мощных СВЧ-транзисторах, работающих в импульсном режиме // Компоненты и технологии. 2010. № 5. С. 15-18.

7. Белоус А. И. СВЧ-электроника в системах радиолокации и связи. Техническая энциклопедия/2-е изд., доп.; В 2-х Кн. Кн. 1: Белоус А. И., Мерданов М. К., Шведов С. В. M.: TEXHOCФЕРA, 2018.

8. Ultrahigh-density $(>0.4 \mu \mathrm{F} / \mathrm{mm} 2)$ trench capacitors in silicon [Электронный ресурс]. - URL: https://www. researchgate.net/publication/282976404_Ultrahighdensity_04_mFmm2_trench_capacitors_in_silicon_Invited

9. Silicon high-density capacitors for power decoupling applications [Электронный ресурс]. - URL: https:// ieeexplore.ieee.org/document/7295975
10. High-Density 3-D Capacitors for Power Systems On-Chip: Evaluation of a Technology based on Silicon Submicrometer Pore Arrays Formed by Electrochemical Etching [Электронный ресурс]. - URL: https://hal.archives-ouvertes.fr/ hal-01443216

11. Astrova E. V. Processing of Macroporous Silicon in Handbook of Porous Silicon // Springer International Publishing- Switzerland-2014.

12. Astrova E. V. Oxidation of Macroporous Silicon in Handbook of Porous Silicon // Springer International Publishing Switzerland- 2014

13. Dielectric layers suitable for high voltage integrated trench capacitors [Электронный ресурс]. -

URL: https://avs.scitation.org/doi/10.1116/1.3525283

14. Dielectric Films for Advanced Microelectronics [Электронный pecypc]. - URL: https://www.wiley.com/en-ru/Dielectric+Fil ms+for+Advanced+Microelectronics-p-9780470065419

15. Ultra Low Profile Silicon Capacitors (down to $80 \mu \mathrm{m}$ ) applied to Decoupling Applications. Results on ESR/ESL [Электронный ресурс]. - URL: https://www.murata.com/-/media/ webrenewal/products/capacitor/siliconcapacitors/technical/ product/ultra_low_profile_silicon_capacitors_down_ to_80micrometres_applied_to_decoupling_esresl.ashx?la=en

16. Патент РФ № 155810 МПК Н01G4/00. Планарный высокочастотный конденсатор/Брюхно Н. А., Громов В. И., Головко О. М., Калинин А. А., Севастьянов Ю. Н., Фроликова А. Ю. заявитель и патентообладатель Акционерное общество «ГРУППА КРЕМНИЙ ЭЛ» № 201511037/07. Заявлено 26.03.2015. Опубликовано 20.10.2015.

17. Патент РФ № 190724 МПК Н01G4/08. Кремниевый конденсатор / Брюхно Н. А., Котова М. Ю., Макарцева О. В., Пугачев В.И заявитель и патентообладатель Акционерное общество «ГРУППА КРЕМНИЙ ЭЛ» № 2019111233. Заявлено 15.04.2019. Опубликовано 10.07.2019.

18. Патент РФ № 190396 МПК Н01G2/00. Кремниевый конденсатор / Брюхно Н. А., Громов В.И., Котова М. Ю., Пугачев В.И., Фроликова А. Ю. заявитель и патентообладатель Акционерное общество «ГРУППА КРЕМНИЙ ЭЛ» № 2018147372. Заявлено 27.12.2018. Опубликовано 01.07.2019. 


\section{Pis Ext ELECTRONICA}

a Hyve event
Самая крупная в России выставка электронных компонентов, модулей и комплектующих

\section{4-16 апреля 2020}

Mockва, МВЦ «Крокус Эксnо»
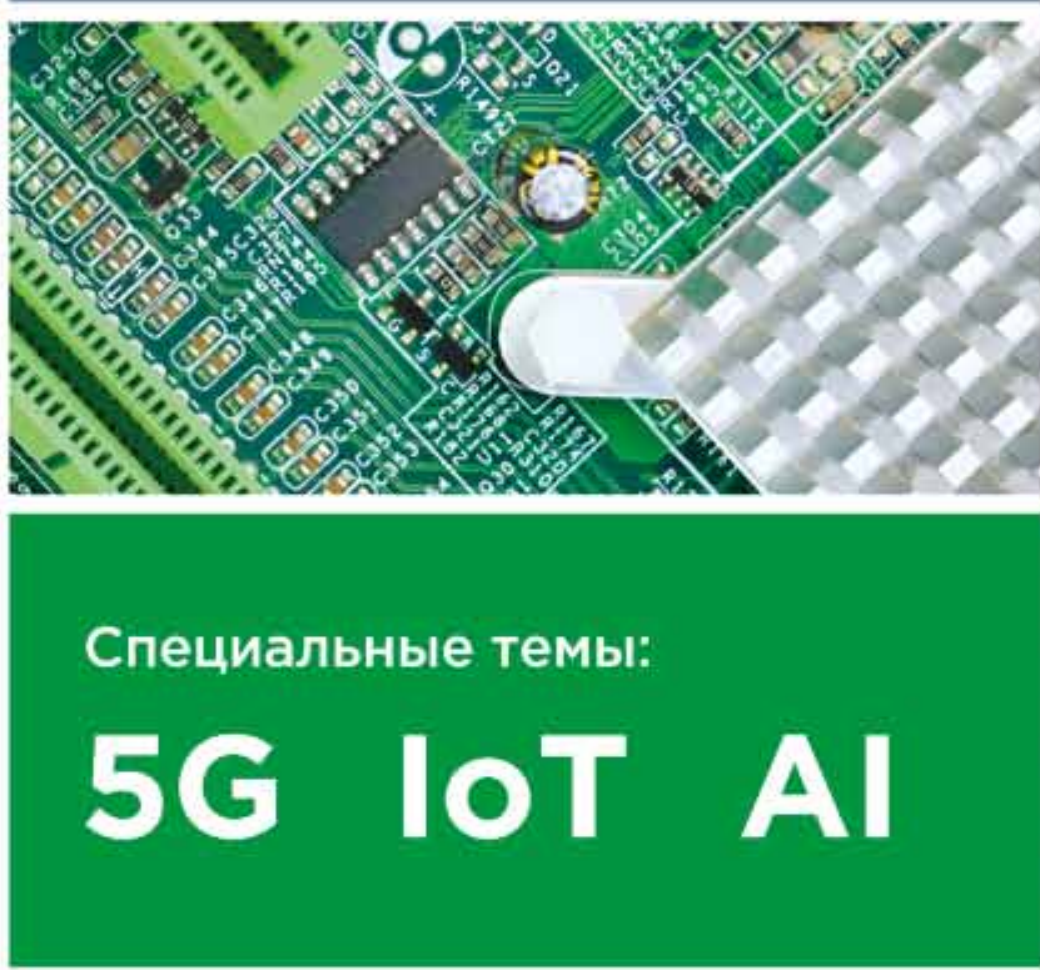

Приглашаем к участию

производителей и поставщиков ЭКБ, комплектующих и ПО для:

- Базовых станций для $5 \mathrm{G}$

- Ядер сети

- Tранспортных ceтей

- Прилохений для 56

- Абонентских устройств

- Систем Iот и искусственного интеллекта

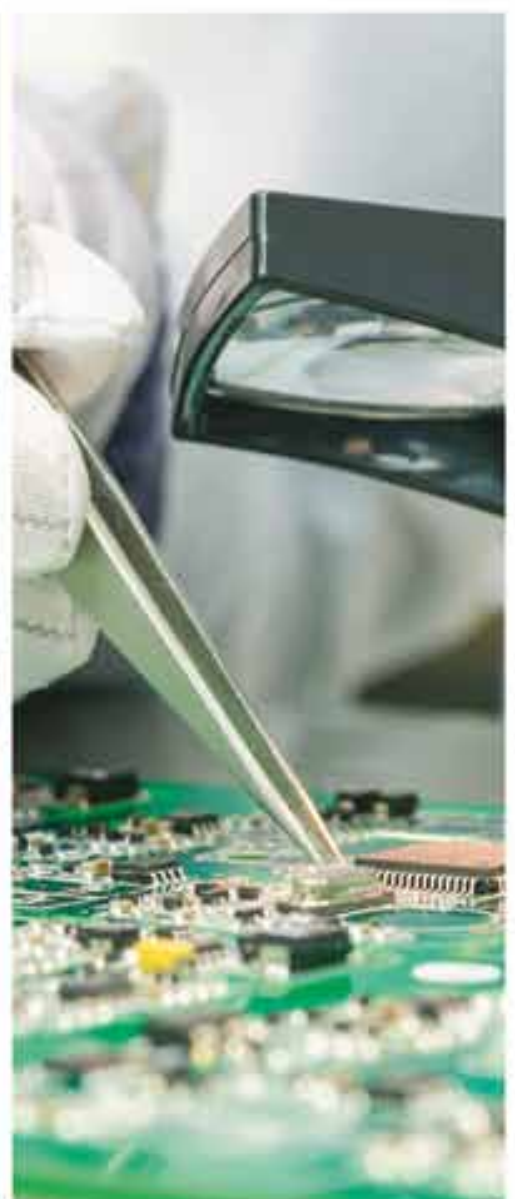

Bau

KOMпOHеHт ycnexa!

expoelectronica.ru 